\section{Cancer around nuclear plant}

\section{Boston}

A US study released last week* shows an increase in the frequency of leukaemia among adults who lived and worked close to the Pilgrim nuclear power plant in Massachusetts in 1978-83. That news is certain to intensify the debate over links between cancer incidence and exposure to a low level of radiation, given that the study follows a US National Cancer Institute (NCI) study that found no increased incidence in cancer deaths around nuclear facilities and British data showing a cluster of cases of childhood leukaemia around the Sellafield nuclear plant (see Nature 347, 216 \& 343, 679; 1990).

The Pilgrim study, carried out by the Massachusetts Department of Public Health, examined the incidence of leukaemia in persons living and working in 22 communities situated near the plant, taking into account how close to the plant they lived and worked and for how long. Although a fourfold incidence in leukaemia was found in people who lived within ten miles of the plant in the period 1979-83, no relationship between leukaemia cases and proximity to the plant was found during 1983-86. Leukaemia normally occurs at a rate of $2-3$ cases per 100,000 population; the Pilgrim study was triggered by data suggesting that the rate close to the plant was double the Massachusetts average.

Assuming that it takes five years for leukaemia to develop, the 1979-83 increase in leukaemia incidence can be linked to a period of higher-than-normal emission of airborne radionuclides from the Pilgrim plant during the mid-1970s. Such emissions fell off considerably after 1978.

Three years ago, the Pilgrim plant was described by federal officials as "the worst-run" nuclear plant in the United States. But even during the periods of increased air emissions, the levels of radiation to which residents were exposed are believed to have been well within the Nuclear Regulatory Commission's limit of 500 millirem per year. At least since 1980, exposure levels are believed to have been within the Environmental Protection Agency's more stringent limit of 25 millirem per year.

Officials at Boston Edison, the utility that operates the Pilgrim plant, criticize the timing and methods of the study. But Daniel Hoffman, a researcher at the US Centers for Disease Control who led the committee that reviewed the results, called the study "well-designed, impressive, and surprising". Hoffman stressed that

*Southeastern Massachusetts Health Study Final Report: Investigation of Leukemia Incidence in 22 Massachusetts Communities 1978-1986. Massachusetts Department of Public Health, Division of Environmental Health Assessment, October 1990. the Pilgrim study is one of the first to correct for confounding factors and says that it "suggests strongly that there may be increased risk levels [from radiation] at levels of exposure far lower than we would expect".

Through interviews, the Pilgrim study collected detailed data about the 313 subjects involved and the length of time they had lived and worked near to the plant. The researchers tracked all types of adult leukaemia except chronic lymphocytic leukaemia (because it is widely considered to be the only type of leukaemia not associated with radiation). Confounding factors, including occupation, age, tobacco consumption and social status were taken into account, along with such factors as the proximity of toxic waste dumps and the origin of the drinking water. During the 1979-83 period, the researchers could even show that the likelihood of developing leukaemia was linked to where and

\section{Washington}

IF there remains any doubt that it is difficult to get private companies to enter the space market, a new report on commercialization at the National Aeronautics and Space Administration (NASA) is sure to remove it. The review*, by the Congressional General Accounting Office $(\mathrm{GAO})$, tells the sad tale of seven projects (worth some $\$ 700$ million) that NASA tried to spin off to industry in 1989. After a year of solicitations with only one taker, six of the projects are now back at NASA, presumably delayed a year at substantial cost - casualties of the administration's fervour for industry participation in the US space programme.

Ranging from a weightlessness laboratory to a robotic arm for the space station, the seven projects represented NASA's best guess at candidates for commercialization in late 1988 when the space agency was in negotiations with the White House to reduce its 1990 budget request, the GAO says. As a compromise, NASA agreed to remove the seven projects from its budget, on the assumption that industry would take them over.

That assumption quickly proved false, GAO found. In five of the projects, "NASA found that commercial aerospace, construction, and finance companies were not willing to invest because they perceived that few or no commercial markets existed". (Several companies did, however, offer to loan

* Space Projects: Improvements Needed in Selecting Future Projects for Private Financing. US General Accounting Office, September, 1990 for how long people lived in the area

Robert Knorr, one of the study's two principal investigators, stressed the differences between the Pilgrim study and NCI's recent mortality study. The Pilgrim study focused on a much smaller and more specific geographic area than did the NCI study, which drew only upon county data that would not detect highly-local increases in cancer. The Pilgrim study also looked at the incidence of disease rather than at only mortality.

After the results of the study were released, people living close to the plant flooded a state telephone 'hotline' number with calls. Massachusetts Governor Michael Dukakis has asked for the state to adopt the strictest radiation emission standard in the country, which would limit exposure of those living near nuclear plants to 10 millirem per year. State researchers have already begun studies on the incidence of childhood leukaemia in the vicinity of the Pilgrim plant and of leukaemia among workers at the plant.

Seth Shulman

\title{
Not so successful selling
}

NASA the money to build the projects itself.) GAO investigators also found that, in the case of three of the projects a space station payload processing laboratory, an instrument processing laboratory and the robotic arm - the design process was as much as 60 per cent completed. To modify the facilities to allow for some commercial use would have required a costly and time-consuming redesign, prospective companies complained.

Among other errors, GAO found that NASA had badly miscalculated commercial financing costs, had underestimated the daunting technical risk of the projects, and had neglected to note that the safety requirements of certain projects limited the qualified private builders to those already working on the project under contract

Except for an orbiting cryogenic pallet, NASA was forced to take all the projects back into its fold, although it was unable to find funding this year for four of them.

In part because of its experiences, NASA set up in July an internal commercial space steering committee. Chaired by NASA deputy administrator J. R. Thompson, the panel is expected to place high priority on finding agency projects that really are suitable for commercialization.

Christopher Anderson

\section{Nature editorial changes}

Rory Howlett has been appointed Book Review/Commentary Editor of Nature. Tim Lincoln is now News and Views Editor, and Maxine Clarke Executive Editor.

NATURE $\cdot$ VOL $347 \cdot 18$ OCTOBER 1990 